\title{
Chapter
}

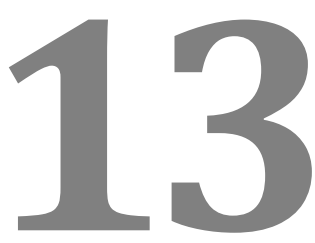

\section{TARGETING STRATEGIES FOR THE TREATMENT OF HELICOBACTER PYLORI INFECTIONS}

Daniela Lopes ${ }^{1}$, Cláudia Nunes ${ }^{1}$, M. Cristina L. Martins ${ }^{2,3}$, Bruno Sarmento $^{2,4}$, and Salette Reis ${ }^{1 *}$

1 UCIBIO/REQUIMTE, Departamento de Ciências Químicas, Faculdade de Farmácia, Universidade do Porto, Porto, Portugal

${ }^{2}$ INEB - Instituto de Engenharia Biomédica, Universidade do Porto,

Porto, Portugal

${ }^{3}$ ICBAS - Instituto de Ciências Biomédicas Abel Salazar, Universidade do Porto, Porto, Portugal

${ }^{4}$ IINFACTS - Instituto de Investigação e Formação Avançada em Ciências e Tecnologias da Saúde, Instituto Superior de Ciências da Saúde-Norte, Gandra-PRD, Portugal 


\section{Contents}

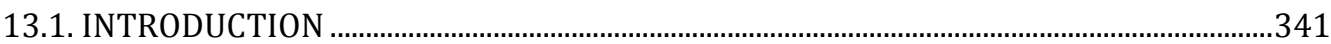

13.2. HOW CAN TARGETING OVERCOME DRUG RESISTANCE? .............................................342

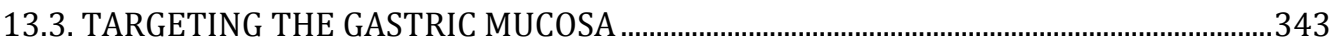

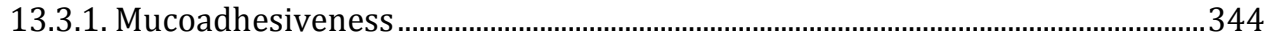

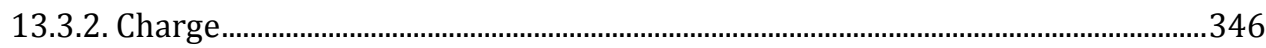

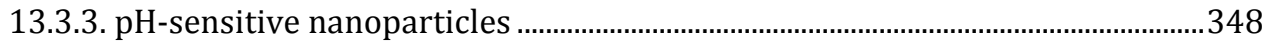

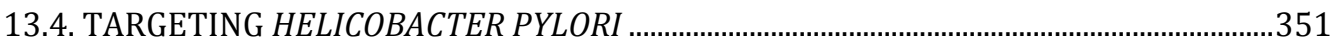

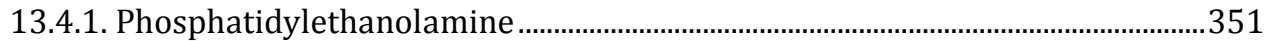

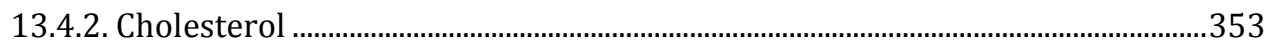

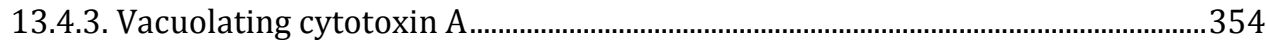

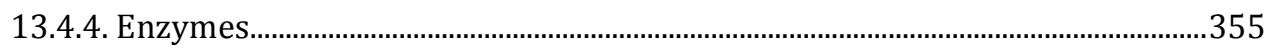

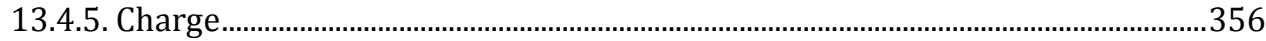

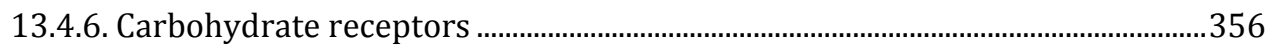

13.5. STUDIES TO EVALUATE THE EFFICACY OF THE TARGETING ….....................................358

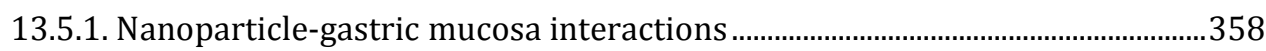

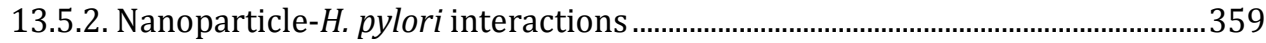

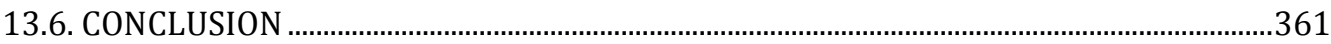

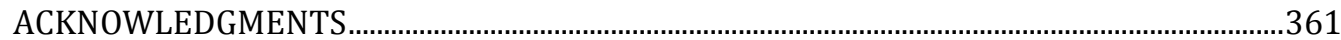

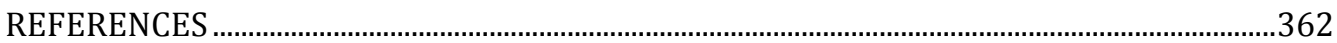




\subsection{INTRODUCTION}

Helicobacter pylori (H. pylori) are gram-negative bacteria which are able to colonise the gastric mucosa due to several factors [1,2]. These virulent factors are both promoters of cytotoxicity and enhancers of its survival, even in an austere environment such as the acidic $\mathrm{pH}$ of the stomach [1,2]. H. pylori are therefore able to penetrate within the mucosa and attach themselves to the surface between the mucous layer and epithelial cells [2,3]. They infect a high percentage of the world's population, with infection rates of approximately $50 \%$ [4]. Once colonised, the majority of the population does not manifest symptoms [4], however, $20 \%$ of the infected population evolves from histological signs of chronic gastritis to gastrointestinal symptoms of gastritis and peptic ulcers [5]. Persistent infections may even evolve into cancer, which led to the classification of the bacterium as a human carcinogen (Group 1) by the International Agency for Research on Cancer (IARC) and the World Health Organization (WHO) [4]. In fact, its relationship to gastric cancer and lymphomas of mucosa-associated lymphoid tissue has been proved [6]. Although there is no clear explanation for it, it has also been related to other extradigestive conditions, such as idiopathic thrombocytopenic purpura, iron deficiency anaemia, ischemic heart disease, stroke, Parkinson's disease and Alzheimer's disease [7].

The severity of $H$. pylori is exacerbated by the difficulty of eradication. There is much controversy regarding the development of an effective vaccine, due to the difficulty of achieving a full protective immune response [8,9]. Clinical trials have generally failed and the investment necessary by pharmaceutical companies is high $[8,9]$. The current approach against $H$. pylori infection is treatment whenever symptoms justify it and includes a drug to reduce the contact between the ulcer and gastric acid, and two or three antibiotics, such as amoxicillin, clarithromycin and metronidazole, for at least 7 days $[10,11]$. The treatment has evolved over the years, but it still has several problems. In fact, eradication rates of $80 \%$ were achieved by prolonging the first-line treatment for 14 days (14-day triple therapy) and in some countries rates of only $20-45 \%$ have been reported $[10,12]$. These rates are still far from those desirable for infectious diseases and those proposed by the WHO [11].

The difficulty of eradicating $H$. pylori is a consequence of a sequence of events. Some drugs, viz. amoxicillin and clarithromycin, are degraded by gastric acid [13], and antibiotics do not remain for a sufficient time in the stomach, resulting in increased difficulty in achieving significant concentrations capable of crossing the mucous layer barrier and reaching the surface where $H$. pylori resides $[14,15]$. These issues both lead to the necessity of higher doses and, consequently, to the exacerbation of gastrointestinal side effects, such as nausea, vomiting and abdominal pain [16]. In fact, the frequency of side effects 
combined with the duration of therapy, which varies between 7 and 14 days, and the discomfort resulting from the multiple doses, causes people to give up on the therapy $[16,17]$. This lack of therapeutic compliance complicates the success of eradication and ultimately it can have a tremendous effect on the development of antibiotics resistance. Actually, the bacterium has developed resistance to several antibiotics, such as metronidazole, with the percentage of resistance at $40 \%$ and $90 \%$ in developed and developing countries, respectively [18].

Different strategies have been attempted in order to overcome these limitations: other approaches to the treatment plan (e.g. bismuth-containing quadruple therapy, sequential and concomitant therapy), use of probiotics and phytomedicine [7,19-21]. A nanotechnology approach has also been applied to the development of effective systems to eradicate H. pylori [22]. Diverse nanoand microparticles have been tested, such as liposomes, polymeric, magnetic and metallic particles [22]. These systems have strong and specific advantages for each kind of nanoparticle. One approach common to the systems in general is the possibility of using passive and active targeting in order to improve the therapy [22]. Targeting allows the enhancement of the affinity between the nano- or microsystem and the gastric mucosa or the H. pylori. In the special case of $H$. pylori infection, vectorization can thus be used to improve the residence time of antibiotics in the stomach and to increase drug concentration at the action site, minimising the side effects. It is also possible to use specific ligands to the bacterium to decrease its adhesion to the gastric mucosa, improving eradication rates [15]. Herein, we will summarise several approaches to targeting both the gastric mucosa and H. pylori.

\subsection{HOW CAN TARGETING OVERCOME DRUG RESISTANCE?}

One of the most worrying problems in the treatment of H. pylori infection is the development of resistance to antimicrobial drugs. Some commonly used drugs, such as metronidazole and clarithromycin, are already resisted by $H$. pylori. Rates of $40 \%$ of resistance to metronidazole have already been reported in developed countries [18]. For clarithromycin, rates of $30 \%$ in America and $92 \%$ in Africa have been reported [23]. Some studies also reported resistance to other drugs, such as amoxicillin, tetracycline and levofloxacin [23]. Multidrug resistance achieved rates of around $9 \%$ in Europe and Asia [23]. Antibiotic resistance is disquieting, especially because persistent infections can lead to gastric cancer and it is difficult to use other antimicrobial drugs, as they are degraded by $\mathrm{pH}[4,13]$.

Nanoparticles can be used to improve the pharmacokinetic properties of drugs and to protect them from the hostile environment of the stomach. 
Improvement of their half-life and a sustained and local release of the drug result in lower doses and a higher efficacy [24]. With a complement of targeting and stimuli-release systems, nanoparticles can be used to achieve higher concentrations of antimicrobial drugs near the bacterium even at low doses [25]. This can minimise side effects and improve the therapeutic efficacy, killing the bacterium and decreasing the potential of developing resistance. This can be improved due to the prospect of using multiple antimicrobial drugs in therapeutic doses [24]. It is unlikely that the bacterium will develop multiple simultaneous gene mutations to resist different mechanisms in the same nanosystem [25]. Given the possibility of using higher doses of the antimicrobial drug, it is possible to saturate transmembrane pumps [25].

Specific mechanisms of the interaction of nanoparticles with bacteria have also proved their usefulness in overcoming bacterial resistance. For instance, the fusion of liposomes with the bacterial membrane and the direct release of its contents inside the bacterium allow the use of sub-minimal inhibitory concentrations (sub-MIC) of antimicrobial drugs [26]. Given the well-known resistance mechanisms related to the membrane, namely the decrease of its permeability and the activation of efflux systems, fusion between liposomes and bacterial membranes can overcome both these mechanisms [26]. Dendrimers have also proved their efficacy since their positive charges promote their link with negative membranes, increasing permeability [25]. Ultimately, they can even destroy the microbial cell membrane [25]. Other kinds of nanoparticles, such as metallic nanoparticles, are unlikely to induce drug resistance for either multiple mechanisms and efficacy even in lower doses [22].

\subsection{TARGETING THE GASTRIC MUCOSA}

There is a close relationship between the gastric mucosa and H. pylori infection. First, these bacteria are able to penetrate within the mucosa and colonise the surface under the mucus layer [1,2]. Their virulence can also damage the gastric mucosa, causing peptic ulcers and ultimately gastric cancer $[1,4]$. The pharmacokinetic of antimicrobial drugs involves absorption and diffusion across the mucus to reach the bacterium, hence it is significantly affected by the gastric mucosa [14,15]. It is also the first barrier that nanoparticles have to cross to reach their target, and therefore, it is important to know the physicochemical properties of the gastric mucosa in order to take advantage of those characteristics to optimise the nanosystem.

One important feature of the mucosa is its hydrophobicity, which avoids the diffusion of hydrogen ions [27]. Their composition in phospholipids, as well as in other surface groups, viz. sialic acid, carboxyl and sulphate groups, play an important role in the interaction with nanoparticles. These surface groups on the mucosa are negatively charged and can establish several interactions with 
nanoparticles, such as electrostatic attraction, hydrogen bond (H-bond) formation and van-der-Waal forces [28-30]. The mucus layer is also characterised by its composition, highly rich in mucins, which are high-molecular-mass oligomeric glycoproteins [31]. Taking this into account, systems with mucoadhesive properties may have an extended residence time at the target and improve contact with biological membranes [30]. The gastric mucosa also has a pH gradient, which is extremely acidic (1 or 2) in the lumen of the stomach and near neutral at the interface between the mucosa and epithelial cells $[32,33]$. This $\mathrm{pH}$ gradient results from the secretion of $\mathrm{HCO}_{3}$ molecules and from the restricted diffusion of protons by the mucus layer [32]. The place to release the antimicrobial drug may thus be chosen using different pH-sensitive nanosystems.

A summary of all characteristics which can be used to treat $H$. pylori infections through the targeting of the gastric mucosa is presented in Figure 1.

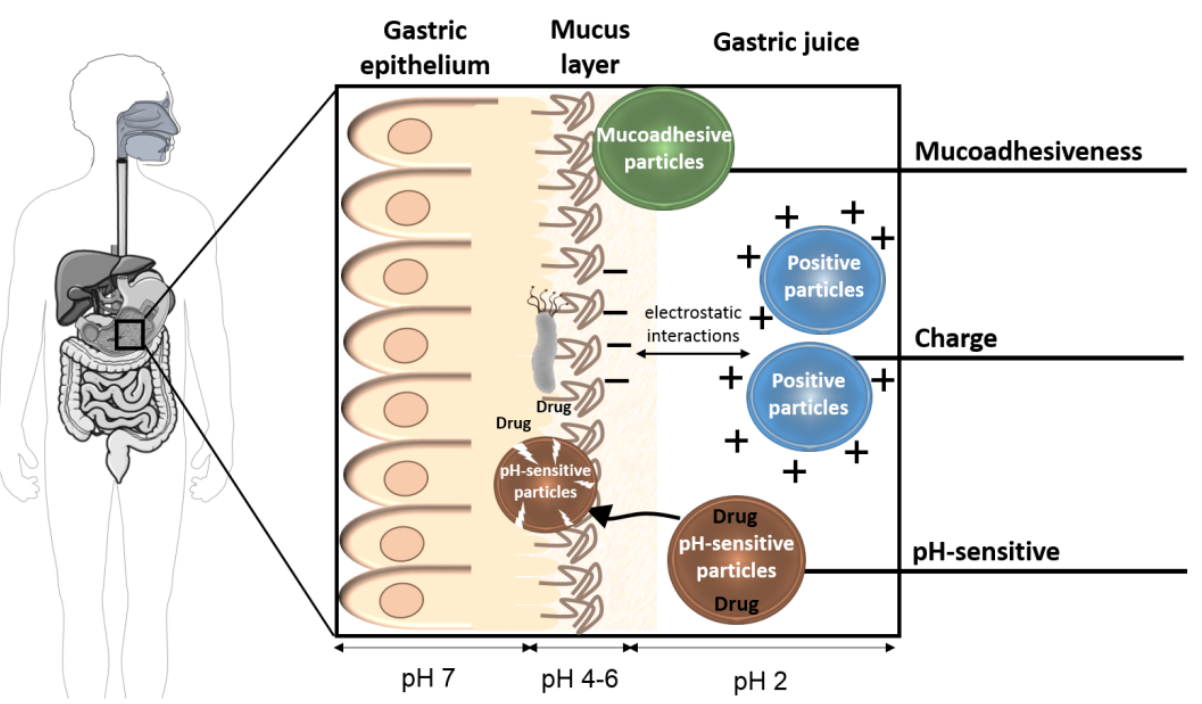

Figure 1. Scheme of the different strategies that can be used to target the gastric mucosa

\subsubsection{Mucoadhesiveness}

Mucoadhesiveness is a characteristic of some compounds reflected in their attraction to a mucosal membrane, which results in a temporary retention [34]. This can be very advantageous both for the increment of the amount of drugs locally released and for the improvement of direct contact with the biological membrane involved in the absorption of the drug [30]. 
Consequently, this strategy has been applied to the treatment of several disorders, through the target of different human mucosa, such as to nasal [35], buccal [36], ocular [37] and vaginal [38] mucosa, among others. Diverse polymers can be used, including natural polymers, such as alginate, chitosan, pectin, xanthan gum, hyaluronic acid and gelatin, synthetic polymers, as poly(ethylene glycol), poly(ethylene oxide), poly(acrylic acid), poly(methacrylic acid) and poly(vinyl amine), and semi-synthetic polymers, namely cellulose derivatives [39].

Due to the complexity of adhesion to the mucosa, several theories have emerged to explain this phenomenon. The electronic theory relies on the existence of electron transference in the origin of electrostatic interactions [34]. In the adsorption theory, other interactions are taken into account, such as H-bonds, van-der-Waals forces, hydrophobic interactions and chemisorption process [34]. Some polymers, namely thiolated polymers or thiomers, can establish disulphide bonds with the mucus gel layer [40]. The wetting theory suggests that the ability of mucoadhesive compounds in the liquid state to extend themselves on the mucosa is due to the surface tension of both mucus and polymers [34]. It is also hypothesised that diffusion events are related to mucoadhesion, which depends on the gradient of concentration, molecular weight, size and mobility of molecules [34]. Adhesion is also related to the force required to detach the material from the mucosa (fracture theory) and with the increased contact area of rough and porous materials (mechanical theory) [34].

Although without certainties concerning the mechanisms involved in mucoadhesion, several bioadhesive polymers have been extensively used. In the special case of $H$. pylori infection, affinity to the gastric mucosa is a useful strategy since the enhancement of the retention time in the stomach is important in overcoming the direct transit through the gastrointestinal tract [41]. Polymeric systems with bioadhesive properties have therefore been used to eradicate $H$. pylori. Polymeric particles have additional advantages, such as their mechanical stability and loading capacity [15]. Several polymers are recognised as biocompatible and some such as gelatin, are classified as GRAS (generally regarded as safe) by the Food and Drug Administration (FDA) [22]. Some mucoadhesive polymers, such as poly(acrylic acid) and poly(allylamine hydrochloride) can decrease the adhesion of $H$. pylori to the gastric mucosa [28].

Table 1 summarises different mucoadhesive polymers reported in nanosystems applied to the treatment of $H$. pylori infection. For instance, poly(acrylic acid) or carbopol was used to develop microspheres. In fact, mucoadhesion properties of carbopol had already been demonstrated by in vitro and in vivo studies [42]. Proteins such as gliadin and gelatin, can also be used, highlighting their additional advantages, which are their nutritional value and the existence of renewable sources [43]. Polymeric carbohydrate molecules, more specifically chitosan, have emerged as a promising drug 
delivery system for $H$. pylori. Due to their positive charge and their mucoadhesiveness, chitosan particles can establish strong electrostatic interactions between their protonated glucosamine residues and the abovementioned negatively charged groups of the gastric mucosa $[44,45]$. Chitosan was therefore used to develop nano- and microparticles loading different antibiotics. In consequence of its broad-spectrum antimicrobial effect, it has also been used in direct action against the bacteria [46,47]. Another approach is the use of chitosan to plug, seal and remove the bacterium from the body [47]. Other polymers with mucoadhesion properties were also used in microparticles composed of mixture of polymers, such as carboxyvinyl polymers, cholestyramine, glycerol monooleate, hydroxypropyl methylcellulose among others.

The problem of extensive mucoadhesiveness is the lower ability to penetrate within the mucosa [29]. Arora et al. (2011) thus modified the charge of chitosan and decreased the particle size to less than the mesh size of mucin fibres [29]. Results revealed the permanency of microparticles in the deepest layers of the mucosa for over $6 \mathrm{~h} \mathrm{[29].}$

Table 1. Summary of different mucoadhesive polymers used in nano- and microsystems to eradicate $H$. pylori through distinct mechanisms

\begin{tabular}{|c|c|c|}
\hline & mer & Mechanism of action/Reference \\
\hline \multicolumn{2}{|c|}{$\begin{array}{c}\text { Poly(acrylic acid) or } \\
\text { carbopol }\end{array}$} & Load amoxicillin $[48,49]$ \\
\hline \multirow{2}{*}{ 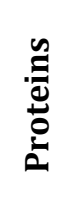 } & Gliadin & $\begin{array}{l}\text { Load acetohydroxamic acid [50]; amoxicillin [51]; } \\
\text { clarithromycin [52]; dual therapy [53] } \\
\text { and triple therapy [54] }\end{array}$ \\
\hline & Gelatin & Load amoxicillin $[55,56]$ \\
\hline \multirow{2}{*}{\multicolumn{2}{|c|}{ Chitosan }} & $\begin{array}{l}\text { Deliver dual therapy }[57,58] \text {; amoxicillin }[17,59] ; \\
\text { tetracycline }[44] ;\end{array}$ \\
\hline & & Antibacterial properties of chitosan $[46,60,61]$ \\
\hline \multicolumn{2}{|c|}{ Copolymers } & $\begin{array}{l}\text { Deliver antibiotics (several systems with different mixture of } \\
\text { polymers, summarised in [22]); probiotics [62]; } \\
\text { phytomedicine [63-66] and antacids [67]. }\end{array}$ \\
\hline
\end{tabular}

\subsubsection{Charge}

As mentioned above, gastric mucosa is negatively charged, and thus positively charged nanoparticles can be used as means of targeting. Bearing in mind that electrostatic interaction may play an important role in the mucoadhesion process, positively charged nanoparticles can be particularly interesting [55]. Wang et al. (2000) demonstrated that positively charged gelatin microspheres 
have increased mucoadhesiveness to nasal mucosa compared to negatively charged particles [55]. Applying this strategy to load amoxicillin, they were able to demonstrate through the use of rhodamine isothiocyanate (RITC)-labelled microspheres in a rat stomach, a higher interaction between the mucosa and modified gelatin microspheres than with gelatin microspheres [55]. The adhesion increased with the increase of the number of amino groups [55]. As several facts may affect the results, such as the labelling with RITC, the perfusion speed and time and the number of microspheres, further studies are still necessary [55]. Cholestyramine also has positively charged amino groups, being used by Umamaheshwari et al. (2003) [68]. The use of a cellulose acetate butyrate polymer to coat these microparticles masked their surface charge and led to a decrease in their mucoadhesiveness [68].

A different approach was developed by Lin et al. (2009), using nanoparticles composed of positively charged chitosan and negatively charged heparin [69]. Once the chitosan:heparin ratio was significantly high, the positive charges of chitosan exceeded the negative charges of heparin [69]. Thus, the final charge of the particle was between $+15 \mathrm{mV}$ and $+33 \mathrm{mV}$ [69]. They were able to demonstrate the adhesion and uptake of nanoparticles by gastric cells using fluorescence studies [69]. These particles were able to interact with sites of H. pylori infection [69].

There are other systems which can be applied to the concept of positively charged nanoparticles. For instance, cationic liposomes have been widely studied for gene therapy and cancer treatment and their application can be extended to target the gastric mucosa [70]. Liposomes in general are recognised for their safety and biocompatibility, however positive charges have been associated with cytotoxicity [70]. In order to overcome this issue, a novel strategy has been adopted, more specifically the cover with biodegradable anionic polymers, which are non-toxic [70]. This would obviously decrease interaction with the gastric mucosa, however, Jain et al. (2009) developed positively charged liposomes composed of egg phosphatidylcholine, cholesterol and stearylamine, and coated with poly(acrylic acid) (negative) and then with poly(allylamine hydrochloride) (positive) [28]. This strategy allowed a coating of liposomes, increasing their stability [28]. Simultaneously, it was possible to take advantage of the positive charge of the outer layer to enhance interaction with the mucosa [28]. Their ability to bind both gastric mucosa and the bacteria, which are negatively charged, was proven through agglutination and adherence studies [28]. Nevertheless, it is necessary to take into account toxicity issues concerning the use of cationic polymers [28]. In fact, in general it has been proved that cytotoxicity is related with the surface charge, as cationic nanoparticles are more toxic than anionic and neutral nanoparticles [71]. 


\subsection{3. pH-sensitive nanoparticles}

Given the $\mathrm{pH}$ gradient of the gastric mucosa, it is possible to develop nanoparticles able to respond to external stimuli. According to the purpose, nanoparticles, either sensitive to acidic $\mathrm{pH}$ or sensitive to neutral $\mathrm{pH}$, have been developed. Taking into account the $\mathrm{pH}$ of the gastrointestinal tract and the extremely acidic $\mathrm{pH}$ of the lumen of the stomach, a local and controlled delivery to acidic $\mathrm{pH}$ can be useful to optimise absorption and minimise premature drug degradation [72]. On the other hand, sensitivity to neutral $\mathrm{pH}$ will allow the release of the content near the bacterium. Both strategies will be discussed herein.

Concerning the release at acidic $\mathrm{pH}$, it is well known that drugs can be degraded at extremely acidic $\mathrm{pH}$, as in the $\mathrm{pH}$ of the lumen of the stomach. For instance, Ramteke et al. (2009) reported that amoxicillin, clarithromycin and omeprazole are degraded in acidic $\mathrm{pH}$ within $3 \mathrm{~h}$ [73]. This degradation can be avoided by encapsulation in a nanoparticle, which can help to conserve an effective concentration at the site of action for long periods of time [73]. Ramteke et al. developed a nanoparticle composed of chitosan and glutamic acid conjugates [73]. Glutamate salt dissolves slowly in acidic $\mathrm{pH}$, which allowed sustained release over 5-6 h [73]. The authors also reported that functionalization with fucose, which is a strategy of active targeting that will be discussed later in this chapter (see 13.4.6. Carbohydrate receptors), decreased the exposure to acidic $\mathrm{pH}$ and consequently retarded the release [73]. Another strategy was developed by Liu et al. (2011), combining buoyancy and mucoadhesion through the use of microspheres of Eudragit ${ }^{\circledR}$ E PO as the modulator of drugs release and glyceryl monooleate as a bioadhesive polymer [74]. The matrix is a polymer soluble at low $\mathrm{pH}$, and thus the drug release rate is higher at acid $\mathrm{pH}$ [74]. There are several other examples with a higher release at extremely acidic $\mathrm{pH}$ than at neutral $\mathrm{pH}$, which were applied to the eradication of $H$. pylori [22]. This is normally due to the instability of the nanosystem and not necessarily in consequence of an initial plan for the design of $\mathrm{pH}$-sensitive nanoparticles, however, a controlled and sustained release can be achieved with the majority of the systems [22]. Nevertheless, the development of $\mathrm{pH}$-sensitive nanoparticles is a strategy widely applied to other diseases. For instance, both cancer and inflammatory diseases are characterised by an acidic extra-cellular environment [75,76]. Thus, $\mathrm{pH}$-sensitive nanoparticles can be used to a target delivery of drugs, decreasing drugs release at physiologic $\mathrm{pH}$, consequently, decreasing side effects and improving therapy [76]. Their application can be extended to diagnostic and gene therapy [76]. Herein, we will summarise some possible strategies for different nanoparticles.

Liposomes are one of the most studied nanoparticles for delivering antimicrobial drugs [22] and it is possible to develop pH-sensitive liposomes. One approach widely studied is the use of polymorphic lipids, highlighting 
unsaturated phosphatidylethanolamine (PE), such as diacetylenic-phosphatidyl-ethanolamine (DAPE), palmitoyl-oleoyl-phosphatidyl-ethanolamine (POPE) and dioleoyl-phosphatidyl-ethanolamine (DOPE) [76]. These phospholipids are usually combined with stabilisers, such as cholesteryl hemisuccinate (CHEMS), which self-assembles into bilayers at neutral pH $[76,77]$. It was shown by Hafez and Cullis (2000) that CHEMS itself has $\mathrm{pH}$-sensitive properties [77]. When in contact with acidic $\mathrm{pH}$, CHEMS became protonated and, consequently, the liposome reverts from a bilayer to an inverted hexagonal II phase [78]. It is also possible to use liposomes stabilised by external compounds sensitive to $\mathrm{pH}$ changes. For instance, carboxyl modified gold nanoparticles were used to stabilise liposomes of 1,2-di-(9Z-octadecenoyl)-3-trimethylammonium-propane (DOTAP) and egg phosphatidylcholine. At $\mathrm{pH}$ values below the $\mathrm{pK}_{\mathrm{a}}$ of the carboxylic group $\left(\mathrm{pK}_{\mathrm{a}}\right.$ around 5), modified gold nanoparticles are protonated and detach from the liposome, increasing its fusion ability [79]. Solid lipid nanoparticles are a possible alternative for application in the eradication of the bacterium, being useful to protect drugs against hostile environments and to control the release of antimicrobial agents [22]. Kashanian et al. (2011) created solid lipid nanoparticles, composed of polysorbate 80, tripalmitin glyceride and $N$-glutaryl PE [80]. Results revealed higher release at acid pH comparatively with physiological pH [80]. Polymeric nanoparticles are also an attractive alternative, using either hydrogels triggered when exposure to a particular $\mathrm{pH}$ range or polymeric nano- or microparticles whose physical properties change in response to an external stimuli $[81,82]$. Different polymeric classes can be used to respond to differences in $\mathrm{pH}$, more specifically poly(methacrylicacid)s, poly(vinylpyridine)s and poly(vinylimidazole)s [82].

Targeting through the release in response to the neutral $\mathrm{pH}$ is possible partly due to the abovementioned secretion of $\mathrm{HCO}_{3}$-molecules and the restricted diffusion of protons through the mucus layer, and partly due to a specific survival mechanism of $H$. pylori [1,32]. More specifically, one of the enzymes secreted by the bacterium, urease, is able to produce ammonia [1]. This secretion results on one strategy for its survival, since it results in the conservation of periplasmic and cytoplasmic $\mathrm{pH}$ near to neutral [1]. It is therefore possible to benefit from the difference between the $\mathrm{pH}$ of the gastric mucosa and the $\mathrm{pH}$ of the medium nearby $H$. pylori. For instance, Thamphiwatana et al. (2013) used small gold nanoparticles modified with chitosan to stabilise liposomes at acidic $\mathrm{pH}$ [83]. Modified gold nanoparticles were charged at acidic $\mathrm{pH}$, being attached to liposomes composed of egg phosphatidylcholine and 1,2-dioleoyl-sn-glycerol-3-phosphate (sodium salt) [83]. At neutral pH, however, modified gold nanoparticles became deprotonated and, consequently, detached from liposomes [83]. This detachment allows the destabilisation of the phospholipid bilayer and fusion with the bacterial membrane (Figure 2) [83]. The efficacy of this method was proved by the increased fusion and higher release rates at $\mathrm{pH} 7.4$ [83]. 
Another approach was used by Silva et al. (2009), who used a mixture of pH-sensitive polymers, more specifically, methacrylic acid and methyl methacrylate ester copolymer, known as Eudragit ${ }^{\circledR} \mathrm{S} 100$ [84]. This polymer is soluble at $\mathrm{pH}$ above 7.0 and, consequently, was used to protect magnetite particles from gastric dissolution and to load amoxicillin [84]. In general, poly(methacrylic acid-co-ethylacrylate) copolymers, commercially known as Eudragits, are widely used to develop pH-sensitive nanoparticles and include a large class of different polymers [85]. They are usually mixed with other polymers [85].
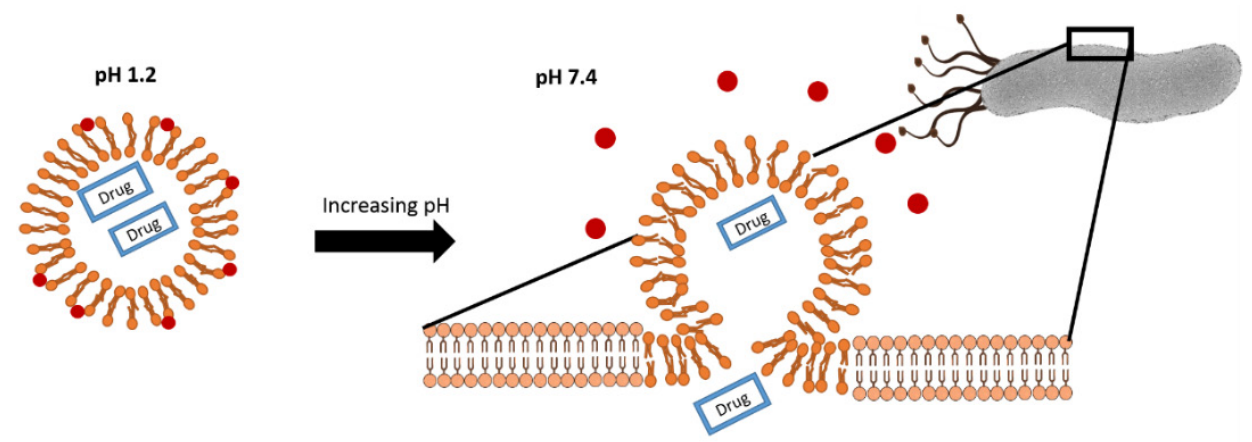

Figure 2. Scheme representative of the action mechanism of $\mathrm{pH}$-sensitive liposomes by the stabilisation with modified gold nanoparticles at acidic $\mathrm{pH}$. When the surrounded medium becomes neutral, modified gold nanoparticles become deprotonated and detach from liposomes. The destabilisation allows the fusion of liposomes with the bacterial membrane (adapted from [83]).

A mixture of chitosan and heparin was used to synthetise $\mathrm{pH}$-sensitive nanoparticles by Lin et al. (2009), for application in H. pylori eradication [86]. At acid $\mathrm{pH}$ (4.5-6.5), which simulates the $\mathrm{pH}$ gradient of the gastric mucosa, chitosan is positively charged and heparin is negatively charged [86], and thus, polyelectrolyte complexes are formed by electrostatic interactions [86]. At $\mathrm{pH}$ 7.0, however, chitosan is deprotonated, which results in the collapse of the nanoparticle [86]. It is also possible to use pH-sensitive hydrogels to incorporate nanoparticles, as was done by Chang et al. (2010) through the incorporation of chitosan/poly- $\gamma$-glutamic acid nanoparticles in calcium-alginate-gelatin hydrogel [87]. Results showed $\mathrm{pH}$-sensitive properties of hydrogel, which protected amoxicillin from the acidic $\mathrm{pH}$ [87]. 


\subsection{TARGETING HELICOBACTER PYLORI}

H. pylori are gram-negative bacteria, which have a spiral-shaped or a coccoid form depending on the hostility of the environment [1,2]. They can colonise an aggressive environment like the stomach due to virulent factors, such as their ability to adhere to the target cells through adhesins, and four to six flagella, which enhance their mobility [1,2]. They are also able to produce urease, cytotoxins and phospholipases which support their subsistence and their toxicity $[1,2]$.

These virulent factors are related to the toxicity of the bacteria and have a close relationship to gastric cancer. They can however be used to eradicate $H$. pylori. Through several mechanisms discussed in this section, it is possible to take advantage of these virulent factors to release the content of the nanoparticle near the bacterium, improving drugs concentration and decreasing side effects. Figure 3 summarises the strategies discussed in this subchapter.

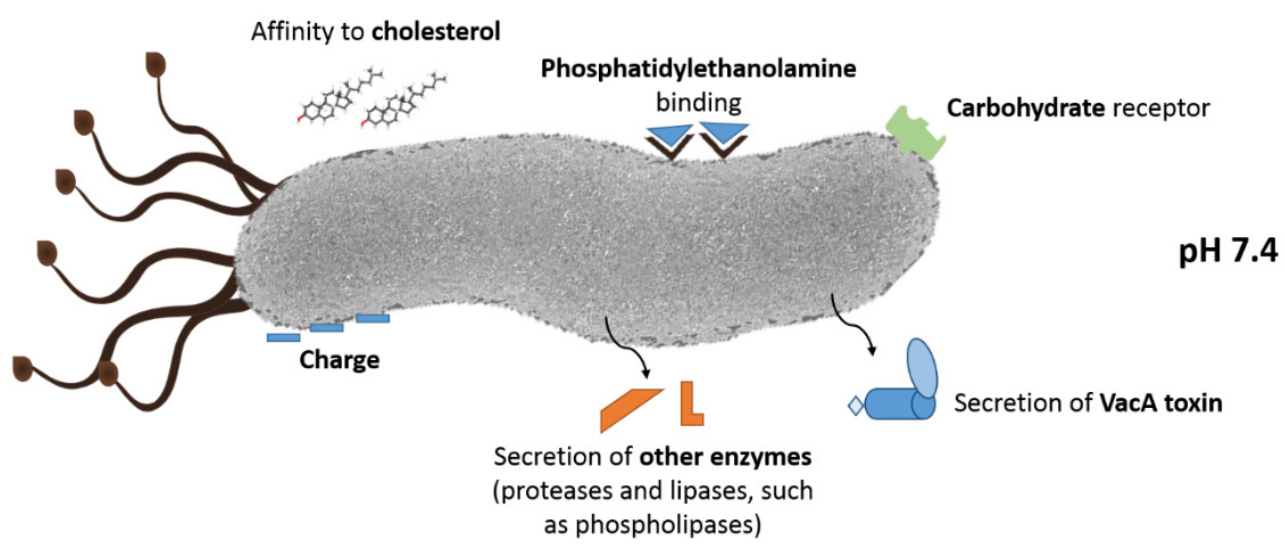

Figure 3. Summary of different virulent factors, which can be used for actively targeting the bacterium

\subsubsection{Phosphatidylethanolamine}

The ability of $H$. pylori to colonise the surface between the mucus gel layer and epithelial cells is directly related to their affinity to gastric glycerolipids [88]. In 1989, Langwood et al. reported the affinity of this bacterium to a lipid demonstrated through solid-phase thin-layer chromatography (TLC) overlay procedure [88]. This lipid was found in higher amounts in human antral mucosa comparatively with fundal mucosa and in adults comparatively to infants [88]. This explained the tendency of colonisation of the antrum and the higher rate of infection in adults [88]. In this work, the glycerolipid recognised by $H$. pylori was isolated from the antrum of human stomach and from human 
erythrocytes [89]. A few years later (1992), Langwood et al. analysed high performance liquid chromatography (HPLC) fatty acid profiles and the ability of the bacterium to bind different phospholipids through TLC overlay [89]. The main conclusion of their work was that the glycerolipid receptor for $H$. pylori is PE [89]. Due to the well-characterised PE from erythrocytes, they only analysed the erythrocytes receptor [89], however, they speculated that the receptor was the same in the human mucosa, possibly with changes in the fatty acids [89]. The hypothesis of Langwood et al. concerning the importance of PE was supported by Dytoc et al. (1993), with the study of adhesion of $H$. pylori to different culture cells [90]. Although other mechanisms are involved, there is an evident correlation between the ability of $H$. pylori to adhere to eukaryotic cells with PE [90].

Taking into account the binding of $H$. pylori to PE in the gastric mucosa, PE can be used as an active targeting strategy to treat $H$. pylori infection. PE constitutes one class of lipids, which assemble into nonbilayer structures under physiological conditions [77]. To overcome this limitation, different approaches have been used, such as a mixture of lipids and phospholipids anchored to polymeric beads (Figure 4). For instance, Bardonnet et al. (2008) used epikuron 170 (phosphatidylcholine $>72 \%, \quad P E>10 \%$, phosphatidylinositol $<3 \%$, lyso-phosphatidylcholine $<4 \%$ and free fatty acids $10 \%)$ and cholesterol to produce liposomes [13]. The formulation was however negatively charged and, given the charge of $H$. pylori, electrostatic repulsion occurred and prevented strong interactions [13]. Double liposomes composed of phosphatidylcholine, cholesterol and PE were also evaluated and both growth inhibition percentage and agglutination assays showed a higher efficiency of the system with PE [91]. Lipobeads composed of an acylated poly(vinyl alcohol) (PVA) core surrounded by a PE bilayer were also used to encapsulate acetohydroxamic acid [15]. Using agglutination assays, it was shown that all $H$. pylori strains recognised PE on the lipobeads as well as commercial PE [15]. Interestingly, lipobeads were able to plug and seal the PE receptor and, consequently, block the adhesion of H. pylori to KATO-III cells, which was concluded from radiolabelling assays [15]. This may imply that this specific targeting can optimise the treatment of $H$. pylori infections not only by a specific binding and local deliver of antibiotics near the bacterium, but also by precluding the attachment of the bacterium to the gastric mucosa. 


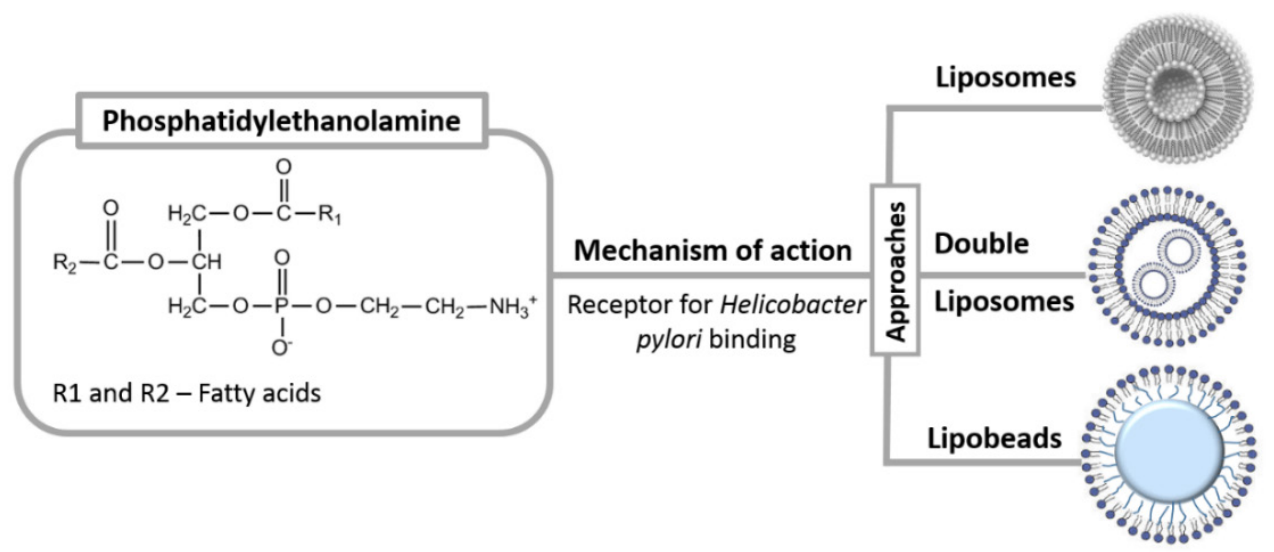

Figure 4. Different approaches to using PE in the active targeting of $H$. pylori. These approaches include liposomes, double liposomes and lipobeads, with a phospholipid bilayer anchored to a polymeric core.

\subsubsection{Cholesterol}

Cholesterol is a steroid with a planar tetracyclic ring system and an extended carbon chain towards the bilayer centre [92]. It is very common in eukaryotic cells, namely in the gastric mucosa [93], and thus, Ansorg et al. (1992) evaluated the affinity of $H$. pylori for cholesterol through several studies, such as gas-liquid chromatography, adsorption procedures and agglutination assays [94]. Results showed a high affinity for cholesterol, and, more interestingly, washings were not sufficient to detach the cholesterol from the bacteria, which can indicate a strong binding or an uptake [94]. This feature of H. pylori strains (both reference and wild strains) does not extend to other bacteria, such as Staphylococcus epidermidis and Escherichia coli [93].

The relation between $H$. pylori and cholesterol is not merely affinity. $H$. pylori follows a cholesterol gradient and is able to extract this lipid from gastric epithelial membranes [95]. In fact, excessive cholesterol enhances phagocytosis of H. pylori and, consequently, inflammation [95]. Nevertheless, the glucosylation of cholesterol by the bacteria allows escape from the phagocytosis [95]. Cholesterol in combination with sphingolipids and phospholipids may create a rigid domain, called lipid rafts [96]. It is believed that the bacteria use these lipid rafts both to deliver bacterial virulence factors and to invade inside the host cells [96]. The knowledge of these mechanisms may be explored to develop drugs able to inhibit lipid rafts [96] or drugs to inhibit cholesterol glucosylation [95], in order to difficult the long-term persistent infection.

This affinity was also explored to test the potential of steroid hormones as antimicrobial agents against $H$. pylori due to their similarity with cholesterol 
[97]. Hosoda et al. (2011) reported that progesterone inhibits the absorption of free cholesterol by the bacteria, suggesting that $H$. pylori may have a steroid-binding protein at the cell surface [97]. This may be very useful in order to develop a new strategy to target the bacteria and several nanoparticles were tested using cholesterol in their composition. For instance, Barbonnet et al. (2008) tested liposomes composed of epikuron 170 or 1,2-dipalmitoyl-sn-glycero-3-phosphocholine (DPPC) to load antimicrobial agents (ampicillin and metronidazole) [13]. Using epifluorescence microscopy, the authors visualized liposome-bacteria interactions that could be explained by the presence of cholesterol [13]. Obonyon et al. (2012) also evaluated liposomes composed of cholesterol, hydrogenated L- $\alpha$-phosphatidylcholine and linolenic acid [18]. They observed that the interaction between liposomes and the bacteria was by fusion and not by adsorption or aggregation [18]. Fusion with the bacterial membrane is a significant advantage because it was reported that this mechanism outrides efflux pumps and barely induces drug resistance $[18,24]$. Both in double liposomes and lipobeads mentioned in the section 13.4.1., they also used cholesterol in the composition of the phospholipid bilayer [15,91]. Thus, positive results in agglutination and adherence studies were possibly enhanced by the presence of cholesterol. As well as the possibility of using cholesterol for specific targeting, it can be useful as a membrane stabiliser, particularly in the case of liposomes [92].

\subsubsection{Vacuolating cytotoxin A}

The ability of the bacteria to produce a factor that induces vacuolization in cultured cells was reported by Leunk et al. in 1988 [98]. In 1992, Cover et al. purified and characterised the vacuolating cytotoxin A (VacA) [99] and over the years knowledge concerning its mechanism and its influence on the toxicity of the bacterium has evolved. In fact, several mechanisms have been associated with this toxin, such as alteration of endo-lysossomal function, permeabilisation of the membrane and pore formation in the plasma membrane [100]. It has also been related to the formation of reactive oxygen species and gastric cancer [101].

Given its effect on the membrane, it is possible to use the VacA toxin to release antimicrobial agents, since near the bacterium the toxin will destabilise the phospholipid bilayer of liposomes through the formation of channels (Figure 5) [13]. The content of the liposomes would thus be locally released. This effect was proven using different liposomes. Moll et al. (1995) demonstrated that VacA toxin induces efflux of potassium from liposomes of asolectin [102]. In 2000, Pagliaccia et al. used liposomes of egg L- $\alpha$-phosphatidylcholine and asolectin in order to prove the self-induced binding of VacA toxin into membranes and its ability to destabilise the membrane, resulting in the release of a fluorescent probe called calcein [103]. It was thus proposed that VacA toxin would bind to the lipid membrane and through a structural change would induce membrane leakage [103]. In fact, it 
is known that VacA toxin binds as a monomer to lipid membrane, with a special affinity to lipid rafts, then oligomerises and penetrates [104]. Consequently, a channel is created, and given this evidence, VacA has been classified as a nonconventional pore-forming toxin with multifunctions [104]. The formation of channels was demonstrated using planar lipid bilayers of egg L- $\alpha$-phosphatidylcholine, dioleoylphosphatidylserine and cholesterol [105]. Using atomic force microscopy, it was possible to see that the channel is a hexamer composed of assembly of monomers of VacA toxin [105].

Another approach is to use heparin nanoparticles, since a subunit of VacA can bind both heparin and heparin sulphate which would likely improve a local release [63].

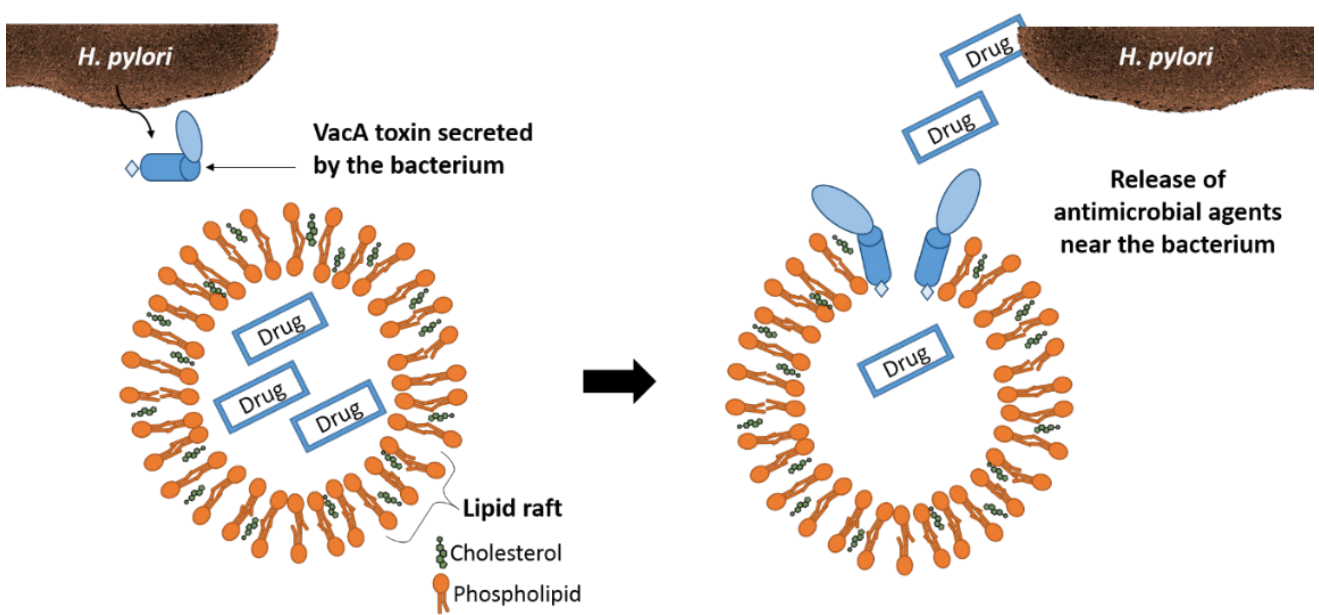

Figure 5. Using the ability of VacA toxin to produce pores in the membrane (based on [104]) to local release of the content of a liposome

\subsubsection{Enzymes}

Similarly to the possibility of use VacA toxin to destabilise the nanoparticle, $H$. pylori is able to secrete different enzymes. For instance, phospholipases secreted by the bacteria are considered pathogenic factors, being related to increased risk of developing ulcers and gastric cancer $[106,107]$. The bacterium secretes several phospholipases (A1, A2, C and D) which can modify and degrade the gastric mucus [106]. The presence of sphingomyelinases in the bacterium has also been reported [108]. They are also able to induce the production of phospholipases from leukocytes [109], and therefore, liposomes or other type of nanoparticles with a phospholipid bilayer, such as a core-shell nanoparticle, can be used and destabilised by these enzymes. They are able to cleave phospholipids in specific locations, modifying their components and, as 
a result, their structure [106]. Consequently, the content will be released near the bacterium and the inflammation. Other enzymes are also secreted by $H$. pylori, such as lipases and proteases [110], which can be used to destabilise lipid and protein nanoparticles.

\subsubsection{Charge}

In 1990, Smith et al. studied the surface hydrophobicity and surface charge of H. pylori in order to understand the mechanisms involved in their adhesion to the gastric mucosa [111]. Different studies were performed, namely hydrophobic interaction chromatography and measurement of contact angles with water, among other things [111]. These complementary methods revealed that $H$. pylori have a hydrophilic and negatively charged surface [111]. The negative charge of $H$. pylori was also reported by Pruul et al. in the same year [112]. Positively charged nanoparticles, mentioned in subchapter 13.3.2, may therefore be useful, and can simultaneously target the gastric mucosa and the bacterium. The importance of the charge was reported by Bardonnet et al. (2008), since less electronegative liposomes showed the best results due to less electrostatic repulsion between the nanoparticle and $H$. pylori [13]. The charge of the bacterium can be changed as a resistance mechanism. For instance, the majority of gram-negative bacteria are able to mask lipid A negative charges, reducing the affinity of positively charged drugs to the outer membrane [113]. In the special case of H. pylori, they are able to modify its majority surface component [lipopolysaccharide (LPS)], through the modification of lipid A [114,115]. The lipid A 1-phosphate group is substituted by a residue of PE in the hydroxyl of the carbon-1 [115]. This results in a reduction of the negative charge [115], which has to be taken into account if the charge only is chosen as a target mechanism.

\subsubsection{Carbohydrate receptors}

Currently, it is well recognised that $H$. pylori can adhere to the gastric mucosa through specific adhesins. In 1998, Ilver et al. identified the adhesin binding fucosylated Lewis $b$ (Leb) histo-blood group antigen (BabA) as a receptor for the adherence of $H$. pylori to the gastric mucosa [116]. A few years later (2002), Mahdavi et al. reported sialyl-dimeric-Lewis x glycosphingolipid (SabA) as a receptor for H. pylori, relating this fact to chronic inflammation [117]. BabA and SabA adhesins differ from each other in terms of amino acid composition and affinity for specific glycans, as the specific affinity of SabA to sialic acid and BabA to fucose $[118,119]$. Given the individual glycan profile of human gastric mucosa, $H$. pylori can benefit from having diverse adhesins [118].

Nanotechnology can take advantage of these adhesins on the surface of the bacterium (Figure 6), such as by using lectins, which are a diverse class of carbohydrates with the advantage of being non-immunogenic [120]. They are also bioadhesives, improving their retention time in the stomach [120]. 
Different lectins, namely Ulex Europaeus Agglutinin I (UEA I) and Conconavalin A (Con A) were tested by Umamaheshwari and Jain (2003) [50]. These lectins were covalently bounded to gliadin nanoparticles, which were chosen due to their mucoadhesiveness, and used to encapsulate acetohydroxamic acid [50]. Agglutination assays showed the efficacy of the binding between both lectins and the bacterium, compared with the absence of agglutination with non-conjugated gliadin nanoparticles [50]. The binding was inhibited by fucose and mannose, reflecting the involvement of the receptors [50]. The results were also confirmed using in situ adherence assays, where the carbohydrate receptors were completely plugged and sealed by the nanoparticles conjugated with lectins [50]. In the presence of these nanoparticles, the binding between $H$. pylori receptors and gastric mucosa carbohydrates was significantly affected, hindering the adhesion to the gastric mucosa [50]. Applying this strategy, triple drug loaded-nanoparticles were developed by Ramteke et al. and the results showed a superior in vivo clearance to that of non-conjugated formulations and free drugs [54]. Con A was also conjugated with ethylcellulose microspheres to encapsulate clarithromycin [121] and in conjugation with Eudragit S100 microspheres to encapsulate amoxicillin trihydrate [122].

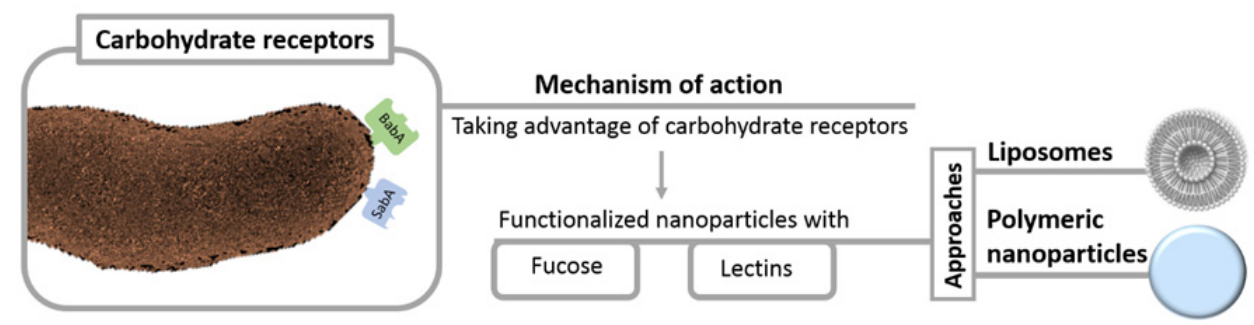

Figure 6. Different approaches to targeting H. pylori using the linkage of fucose and lectins to carbohydrate receptors in the bacterium

Bardonnet et al. (2008) developed liposomes of DPPC or epikuron in conjugation with a synthetic glycolipid, which was composed of a cholesterol group, four ethylene glycol units and fucose [13]. The same group had already proved that liposomes with fucosyl neoglycolipids on the surface were stable [123]. Epifluorescence studies showed an enhancement of the interaction of liposomes with the bacterium when the fucosylated neoglypid was present [13]. They were able to bind both spiral and coccoid forms [13]. However, this was not possible in all strains, since some $H$. pylori strains do not express babA2 gene and, consequently, do not have the receptor to bind the fucose [13]. 
Fucose was also used in other kinds of nanoaparticles, such as conjugated with chitosan-glutamate nanoparticles to deliver amoxicillin, clarithromycin and omeprazole [73]. The specific binding was confirmed through agglutination assays [73]. The targeting improved the clearance of the bacteria in vivo [73]. Lin et al. (2013) developed genipin-cross-linked fucose-chitosan/heparin nanoparticles to encapsulate amoxicillin and demonstrated the targeting through electronic microscopy and fluorescence studies [124].

\subsection{STUDIES TO EVALUATE THE EFFICACY OF THE TARGETING}

After optimising a nanoparticle for different parameters, such as size, zeta-potential, entrapment efficiency, profile of release at different $\mathrm{pH}$ and stability, it is essential to evaluate their efficacy. General studies can be performed, such as in vitro $H$. pylori growth inhibition, and specific assays can be chosen to evaluate their interaction with either the gastric mucosa or the bacterium.

\subsubsection{Nanoparticle-gastric mucosa interactions}

Mucoadhesiveness is one strategy extensively applied in the case of $\mathrm{H}$. pylori infection. There are several possibilities for evaluating this property, including indirect and direct methods [39]. Indirect methods include microgravimetric methods, atomic force microscopy and diffusion/particle tracking methods [39]. Direct methods involve cytoadhesion methods and ex vivo and in vivo administration and imaging [39]. Herein, we will focus on different assays applied directly to the study of nano- and microparticles to be applied in the eradication of H. pylori. For instance, a piece of rat stomach, tied onto plastic, can be used to spread nanoparticles [125], then, disintegrating test apparatus is used to promote regular up and down movements of the system with the tissue and distilled water [125]. After $4 \mathrm{~h}$, the number of microspheres still adhered is counted [125]. A more complex assay was performed by Liu et al. (2005), using cut stomachs incubated with microspheres in a chamber at $93 \%$ relative humidity and room temperature [126]. After $20 \mathrm{~min}$, tissues were fixed on a polyethylene support at an angle of $45^{\circ}$ and washed with $\mathrm{pH} 1.3$ $\mathrm{HCl}$-physiological saline for $5 \mathrm{~min}\left(22 \mathrm{ml} \mathrm{min}^{-1}\right)$ [126]. The remaining microspheres were counted [126]. The results can be expressed in different ways, such as by the percentage of the remaining microspheres [126] or by the percentage of mucoadhesion, which can be calculated using the Equation 1 [127].

$$
\% \text { Mucoadhesion }=\frac{W_{0}-W_{1}}{W_{0}} \times 100
$$


where $w_{0}$ and $w_{1}$ are the weight of microspheres applied initially and the weight of microspheres rinsed off, respectively.

Scanning electron microscopy was also used to monitor the in vitro wash-off test for mucoadhesive microspheres at different time points [128].

Another approach was applied by Wang et al. (2000) using male wistar rats to remove stomach under anesthesia [55]. After washing the content of the stomach, RITC-labeled microspheres suspended in simulated gastric fluid were filled into the stomach [55]. After incubation for $30 \mathrm{~min}$, the stomach was washed and perfused with simulated gastric fluid for $30 \mathrm{~min}\left(1.0 \mathrm{ml} \mathrm{min}{ }^{-1}\right)$ [55]. Fluorescence spectrophotometry was then used to determine the percentage of microspheres retained in the stomach after degradation of the microspheres with trypsine [55].

Another in vivo approach was used by Liu et al. (2005), using thirty rats divided into six groups, of which three were administered with microspheres and three with placebo [126]. They were sacrificed at 2, 4 and $7 \mathrm{~h}$ and microspheres remained in the gastrointestinal tract were counted [126]. In vivo mucoadhesion was evaluated by Ramteke et al. (2008) using nanoparticles containing barium sulphate as a contrast agent [54]. The authors used albino rats which were recorded by X-ray photographs at different times [54].

It is also possible to evaluate the ability of the nanoparticle to block the binding of $H$. pylori to mucosa. For this purpose, Umamaheshwari et al. (2004) performed adherence assays using labelled H. pylori and KATO-III cells (gastric epithelial cells) [15]. H. pylori preincubated with lipobeads were washed and added to the suspension of KATO-III cells [15]. Six washes were used to remove non-adherent bacteria [15]. The number of bacteria adherent was counted using disintegrations per minute in a scintillation counter after trypsination to remove adherent bacteria and KATO-III cells from the wells [15]. In situ adherence assays can also be used for the same purpose [15]. Fluorescein isothiocyanate-labeled (FITC-labeled) bacteria preincubated with lipobeads for $2 \mathrm{~h}$ were washed and then added to tissue sections of samples of oesophagus, stomach, duodenum and colon [15]. In situ binding was demonstrated through fluorescence microscopy [15].

\subsubsection{Nanoparticle- $H$. pylori interactions}

Agglutination assays can be performed by mixing the same amount of bacterial suspension and the nanoparticle formulation [50]. The agglutination reaction can then be scored according to the size of clumps [50]. This assay can also be used to confirm whether a specific ligand is involved, pre-incubating with specific inhibitors of agglutination [50]. The agglutination can be however affected by the self-aggregation of some strains [13]. Bardonnet et al. (2008) used epifluorescence studies, with the bacteria stained with DAPI by fluorescent in situ hybridization technique and liposomes marked with NBD-PC 
[13]. The mixture was observed by epifluorescence microscopy and the superimposition of the two dyes suggested that liposomes were aggregated around H. pylori [13].

Another labelling technique was used by Gonçalves et al. (2013), using H. pylori previously marked with FITC [61]. The interaction with auto-fluorescent chitosan microspheres was demonstrated through confocal laser scanning microscopy (Figure 7) [61].

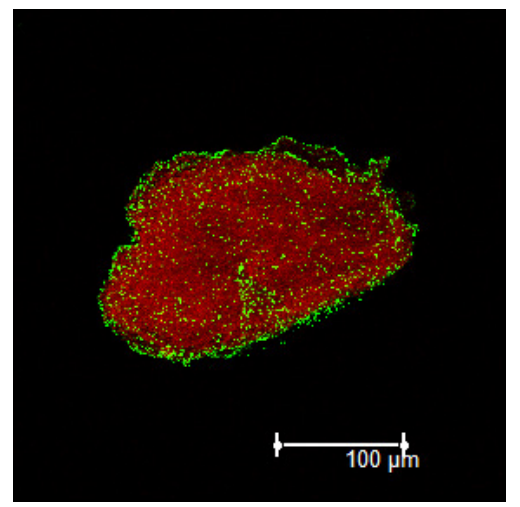

Figure 7. Confocal microscopy image of chitosan microspheres (in red) with adherent FITC-labelled H. pylori strain (17875/Leb) (in green) under $\mathrm{pH} 6.0$ (adapted from [61]). The scale-line is representative of the whole system.

Quantification of adhesion of ${ }^{35}$ S-labeled $H$. pylori can be achieved using a luminescence counter through the determination of the radioactivity of each well of polyethylene terephthalate plates [61]. Knowing the concentration in colony-forming unit (CFU).ml-1 of the initial $H$. pylori inoculum $\left(C_{\mathrm{Hp}}^{\mathrm{i}} C\right)$, the activity of $H$. pylori adherent in c.p.m. $\left(A_{\mathrm{Hp}}^{\mathrm{mic}} A\right)$, the activity of the initial $H$. pylori inoculum in c.p.m.ml-1 $\left(A_{\mathrm{Hp}}^{\mathrm{i}} A\right)$ and knowing the number of microspheres of each well $\left(N_{\text {mic }}\right)$, which can be counted using a camera coupled to a stereomicroscope, it is possible to determine the number of adherent bacteria per microsphere (Equation 2) [61].

$$
\frac{\text { Number of adherent bacteria }}{\text { microsp here }}(\text { CFU per microsphere })=\frac{\left(C_{\mathrm{Hp}}^{\mathrm{i}} \times A_{\mathrm{Hp}}^{\mathrm{mic}} \div A_{\mathrm{Hp}}^{\mathrm{i}}\right)}{N_{\text {mic }}}
$$

Other techniques of microscopy can be used, such as transmission electron microscopy (TEM) to demonstrate both the distribution of the nanoparticle around the bacteria and their effect on the morphology of the bacteria [124]. 


\subsection{CONCLUSION}

Nanotechnology is a growing and promising field, which has been extensively studied in order to overcome limitations of current therapies in several diseases. In the special case of $H$. pylori infection, nanoparticles have been proving their utility in improving the efficacy of antibiotics, by protecting them from the environment and by promoting a controlled, sustained and local delivery of drugs. The local delivery can be achieved by targeting gastric mucosa or the bacterium.

In the development of a targeting nanoparticle is important to initially choose the nanoparticle and the strategy most suitable for the purpose in mind. In this process, it is essential to take into account the balance between various approaches. Extreme mucoadhesiveness may be prejudicial to penetration within the mucosa due to the decrease of mobility and it is affected by the high turnover of the gastric mucosa [29,129]. The $\mathrm{pH}$ gradient is also a key point, since the gastric medium is around $\mathrm{pH} 1.2$ whereas the surrounding medium of the bacterium is at neutral $\mathrm{pH}$. This large $\mathrm{pH}$ gradient can also affect the charge of the nanoparticles if it includes the $\mathrm{pK}_{\mathrm{a}}$ of the nanoparticles components. The charge of the bacterium can be changed by resistance mechanisms, and therefore it is important to take these possible changes into account. Other mechanisms, such as translocation, coordinated response of tissues, enzymes and toxicokinetics, may affect the specificity of the targeting and even be involved in toxicity mechanisms [130].

Above all, the possibility of combining different strategies in order to increase the local release is very attractive, and advantageous to decreasing the development of antibacterial resistance.

\section{ACKNOWLEDGMENTS}

Daniela Lopes and Cláudia Nunes thank FCT (Fundação para a Ciência e Tecnologia) for the Grant from the International Doctoral Programme on Cellular and Molecular Biotechnology Applied to Health Sciences (BiotechHealth) (PD/BD/105957/2014) and for the Post-Doc Grant (SFRH/BPD/81963/2011), respectively. Funding from FCT (UID/Multi/04378/2013) is also acknowledged. 


\section{REFERENCES}

1. L. Boyanova, I. Mitov, B. Vladimirov, Helicobacter pylori, Caister Academic Press, Norfolk, UK, 2011.

2. H.L.T. Mobley, G.L. Mendz, S.L. Hazell, (Eds.), Helicobacter pylori: physiology and genetics, ASM Press, Washington DC, USA, 2001.

3. $\quad$ H.L.T. Mobley. Gastroenterology 113 (1997) S21-S28.

4. IARC Working Group on the Evaluation of the Carcinogenic Risks to Human, Lyon, France, 2009.

5. $\quad$ S.S. Kim, V.E. Ruiz, J.D. Carroll, S.F. Moss. Cancer Lett. 305 (2011) 228-238.

6. P.L. Bardonnet, V. Faivre, W.J. Pugh, J.C. Piffaretti, F. Falson. J. Control. Release 111 (2006) 1-18.

7. S.D. Georgopoulos, V. Papastergiou, S. Karatapanis. Expert Opin. Pharmacother. 14 (2013) 211-223.

8. P. Sutton, Y.T. Chionh. Expert Rev. Vaccines 12 (2013) 433-441.

9. A. Müller, J.V. Solnick. Helicobacter 16 (2011) 26-32.

10. A. Zullo, C. Hassan, L. Ridola, V.d. Francesco, D. Vaira. Eur. J. Intern. Med. 24 (2012) 16-19.

11. P. Malfertheiner, F. Megraud, C.A. O'Morain, J. Atherton, A.T. Axon, F. Bazzoli, G.F. Gensini, J.P. Gisbert, D.Y. Graham, T. Rokkas, E.M. El-Omar, E.J. Kuipers. Gut 61 (2012) 646-664.

12. M. Selgrad, P. Malfertheiner. Curr. Opin. Pharmacol. 8 (2008) 593-597.

13. P.-L. Bardonnet, V. Faivre, P. Boullanger, J.-C. Piffaretti, F. Falson. Eur. J. Pharm. Biopharm. 69 (2008) 908-922.

14. L. Yang, J. Eshraghi, R. Fassihi. J. Control. Release 57 (1999) 215-222.

15. R.B. Umamaheshwari, N.K. Jain. J. Control. Release 99 (2004) 27-40.

16. A. Armuzzi, F. Cremonini, F. Bartolozzi, F. Canducci, M. Candelli, V. Ojetti, G. Cammarota, M. Anti, A. De Lorenzo, P. Pola, G. Gasbarrini, A. Gasbarrini. Aliment. Pharmacol. Ther. 15 (2001) 163-169.

17. J.K. Patel, M.M. Patel. Curr. Drug Deliv. 4 (2007) 41-50.

18. M. Obonyo, L. Zhang, S. Thamphiwatana, D. Pornpattananangkul, V. Fu, L. Zhang. Mol. Pharm. 9 (2012) 2677-2685.

19. J.-M. Liou, C.-C. Chen, M.-J. Chen, C.-C. Chen, C.-Y. Chang, Y.-J. Fang, J.Y. Lee, S.-J. Hsu, J.-C. Luo, W.-H. Chang, Y.-C. Hsu, C.-H. Tseng, P.-H. Tseng, H.-P. Wang, U.-C. Yang, C.-T. Shun, J.-T. Lin, Y.-C. Lee, M.-S. Wu. Lancet 381 (2013) 205-213.

20. A. Patel, N. Shah, J.B. Prajapati. J. Microbiol. Immunol. Infect. 47 (2013) 1-9.

21. J. Vítor, F.F. Vale. FEMS Immunol. Med. Microbiol. 63 (2011) 153-164.

22. D. Lopes, C. Nunes, M.C. Martins, B. Sarmento, S. Reis. J. Control. Release 189 (2014) 169-186.

23. W. Wu, Y. Yang, G. Sun. Gastroenterol. Res. Pract. 2012 (2012) 1-8.

24. A.J. Huh, Y.J. Kwon. J. Control. Release 156 (2011) 128-145.

25. $\quad$ R.Y. Pelgrift, A.J. Friedman. Adv. Drug Deliv. Rev. 65 (2013) 1803-1815.

26. Z. Drulis-Kawa, A. Dorotkiewicz-Jach. Int. J. Pharm. 387 (2010) 187-198.

27. W. Bernhard, A.D. Postle, M. Linck, K.-F. Sewing. Biochim. Biophys. Acta 1255 (1995) 99-104.

28. P. Jain, S. Jain, K.N. Prasad, S.K. Jain, S.P. Vyas. Mol. Pharm. 6 (2009) 563-603.

29. S. Arora, S. Gupta, R.K. Narang, R.D. Budhiraja. Sci. Pharm. 79 (2011) 673-694.

30. C.-M. Lehr, H.E. Boddé, J.A. Bouwstra, H.E. Junginger. Eur. J. Pharm. Sci. 1 (1993). 
31. H. Nordman, J.R. Davies, I. Carlstedt. Biochem. J. 331 (1998) 687-694.

32. A. Allen, G. Flemström. Am. J. Physiol. 288 (2005) C1-C19.

33. A.A. Salyers, D.W. Dixie, Bacterial Pathogenesis: A Molecular Approach, $2^{\text {nd }}$ ed., ASM Press, Washington DC, USA, 2002.

34. V.V. Khutoryanskiy. Macromol. Biosci. 11 (2011) 748-764.

35. M.I. Ugwoke, R.U. Agu, N. Verbeke, R. Kinget. Adv. Drug Deliv. Rev. 57 (2005) 1640-1665.

36. N. Salamat-Miller, M. Chittchang, T.P. Johnston. Adv. Drug Deliv. Rev. 57 (2005) 1666-1691.

37. A. Ludwig. Adv. Drug Deliv. Rev. 57 (2005) 1595-1639.

38. C. Valenta. Adv. Drug Deliv. Rev. 57 (2005) 1692-1712.

39. A. Sosnik, J. das Neves, B. Sarmento. Prog. Polym. Sci. 39 (2014) 2030-2075.

40. A. Bernkop-Schnurch. Adv. Drug Deliv. Rev. 57 (2005) 1569-1582.

41. L.M. Ensign, R. Cone, J. Hanes. Adv. Drug Deliv. Rev. 64 (2012) 557-570.

42. Y. Akiyama, N. Nagahara, T. Kashihara, S. Hirai, H. Toguchi. Pharm. Res. 12 (1995) 397-405.

43. A.O. Elzoghby, W.M. Samy, N.A. Elgindy. J. Control. Release 161 (2012) 38-49.

44. R. Hejazi, M. Amiji. Int. J. Pharm. 235 (2002) 87-94.

45. I.C. Gonçalves, P.C. Henriques, C.L. Seabra, M.C.L. Martins. Expert Rev. AntiInfect. Ther. (2014) 1-12.

46. D. Luo, J. Guo, F. Wang, J. Sun, G. Li, X. Cheng, M. Chang, X. Yan. J. Biomater. Sci. 20 (2009) 1587-1596.

47. F. Nogueira, I.C. Goncalves, M.C. Martins. Acta Biomater. 9 (2013) 5208-5215.

48. M. Cuña, M.J. Alonso, D. Torres. Eur. J. Pharm. Biopharm. 51 (2001) 199-205.

49. S. Harsha. Int. J. Nanomed. 7 (2012) 4787-4796.

50. $\quad$ R.B. Umamaheshwari, N.K. Jain. J. Drug Target. 11 (2003) 415-424.

51. R.B. Umamaheshwari, S. Ramteke, N.K. Jain. AAPS PharmSciTech 5 (2004) 1-9.

52. S. Ramteke, R.B. Umamaheshwari, N.K. Jain. Indian J. Pharm. Sci. 68 (2006) 479-484.

53. S. Ramteke, N.K. Jain. J. Drug Target. 16 (2008) 65-72.

54. S. Ramteke, N. Ganesh, S. Bhattacharya, N.K. Jain. J. Drug Target. 16 (2008) 694-705.

55. J. Wang, Y. Tauchi, Y. Deguchi, K. Morimoto, Y. Tabata, Y. Ikada. Drug Deliv. 7 (2000) 237-243.

56. $\quad$ S. Harsha. Drug Des. Dev. Ther. 7 (2013) 1027-1033.

57. S. Shah, R. Qaqish, V. Patel, M. Amiji. J. Pharm. Pharmacol. 51 (1999) 667-672.

58. A. Portero, C. Remunan-Lopez, M.T. Criado, M.J. Alonso. J. Microencapsulation 19 (2002) 797-809.

59. J. Patel, P. Patil. J. Microencapsulation 29 (2012) 398-408.

60. M. Fernandes, I.C. Goncalves, S. Nardecchia, I.F. Amaral, M.A. Barbosa, M.C. Martins. Int. J. Pharm. 454 (2013) 116-124.

61. I.C. Goncalves, A. Magalhaes, M. Fernandes, I.V. Rodrigues, C.A. Reis, M.C. Martins. Acta Biomater. 9 (2013) 9370-9378.

62. J.A. Ko, H.J. Lim, H.J. Park. Process Biochem. 46 (2011) 631-635.

63. C.-H. Chang, W.-Y. Huang, C.-H. Lai, Y.-M. Hsu, Y.-H. Yao, T.-Y. Chen, J.-Y. Wu, S.-F. Peng, Y.-H. Lin. Acta Biomater. 7 (2011) 593-603.

64. X. Zhu, D. Zhou, S. Guan, P. Zhang, Z. Zhang, Y. Huang. J. Mater. Sci. Mater. Med. 23 (2012) 983-990. 
65. P. Pan-In, A. Tachapruetinun, N. Chaichanawongsaroj, W. Banlunara, S. Suksamrarn, S. Wanichwech-Arungruang. Nanomedicine (2013).

66. M. Ali, K. Dhar, M. Jain, V. Pandit. J. Adv. Pharm. Technol. Res. 5 (2014) 48-56.

67. R.P. Raffin, D.S. Jornada, M.I. Ré, A.R. Pohlmann, S.S. Guterres. Int. J. Pharm. 324 (2006) 10-18.

68. R.B. Umamaheshwari, S. Jain, N.K. Jain. Drug Deliv. 10 (2003) 151-160.

69. Y.-H. Lin, C.-H. Chang, Y.-S. Wu, Y.-M. Hsu, S.-F. Chiou, Y.-J. Chen. Biomaterials 30 (2009) 3332-3342.

70. G. Shim, M.-G. Kim, J.Y. Park, Y.-K. Oh. Asian J. Pharm. Sci. 8 (2013) 72-80.

71. M.Y. Wani, M.A. Hashim, F. Nabi, M.A. Malik. Adv. Phys. Chem. 2011 (2011) 1-15.

72. V.R. Patel, M.M. Amiji. Pharm. Res. 13 (1996) 588-593.

73. S. Ramteke, N. Ganesh, S. Bhattacharya, N.K. Jain. J. Drug Target. 17 (2009) 225-234.

74. Y. Liu, J. Zhang, Y. Gao, J. Zhu. Int. J. Pharm. 413 (2011) 103-109.

75. L. Tian, Y.H. Bae. Colloids Surf. B 99 (2012) 116-126.

76. X. Liu, G. Huang. Asian J. Pharm. Sci. 8 (2013) 319-328.

77. I.M. Hafez, P.R. Cullis. Biochim. Biophys. Acta 1463 (2000) 107-114.

78. S. Simões, V. Slepyshkin, N. Düzgünes, M.C.P.d. Lima. Biochim. Biophys. Acta 1515 (2001) 23-27.

79. D. Pornpattananangkul, S. Olson, S. Aryal, M. Sartor, C.M. Huang, K. Vecchio, L. Zhang. ACS nano 4 (2010) 1935-1942.

80. S. Kashanian, A.H. Azandaryani, K. Derakhshandeh. Int. J. Nanomed. 6 (2011) 2393-2401.

81. R.A. Siegel. J. Control. Release 190 (2014) 337-351.

82. H. Priya James, R. John, A. Alex, K.R. Anoop. Acta Pharm. Sin. B 4 (2014) 120-127.

83. S. Thamphiwatana, V. Fu, J. Zhu, D. Lu, W. Gao, L. Zhang. Langmuir 29 (2013) 12228-12233.

84. É.L. Silva, J.F. Carvalho, T.R.F. Pontes, E.E. Oliveira, B.L. Francelino, A.C. Medeiros, E.S.T. do Egito, J.H. Araujo, A.S. Carriço. J. Magn. Magn. Mater. 321 (2009) 1566-1570.

85. X.Q. Wang, Q. Zhang. Eur. J. Pharm. Biopharm. 82 (2012) 219-229.

86. Y.H. Lin, C.H. Chang, Y.S. Wu, Y.M. Hsu, S.F. Chiou, Y.J. Chen. Biomaterials 30 (2009) 3332-3342.

87. C.-H. Chang, Y.-H. Lin, C.-L. Yeh, Y.-C. Chen, S.-F. Chiou, Y.-M. Hsu, Y.-S. Chen, C.-C. Wang. Biomacromolecules 11 (2010) 133-142.

88. C.A. Lingwood, A. Pellizari, H. Law, P. Sherman, B. Drumm. Lancet (1989) 238-241.

89. C.A. Lingwood, M. Huesca, A. Kuksis. Infect. Immun. 60 (1992) 2470-2474.

90. M. Dytoc, B. Gold, M. Louie, M. Huesca, L. Fedorko, S. Crowe, C. Lingwood, J. Brunton, P. Sherman. Infect. Immun. 61 (1993) 448-456.

91. D.Y. Singh, N.K. Prasad. Pharmazie 66 (2011) 268-273.

92. T.P. McMullen, R.N. McElhaney. Curr. Opin. Colloid Interface Sci. 1 (1996) 83-90.

93. C. Trampenau, K.-D. Müller. Microbes Infect. 5 (2003) 13-17.

94. R. Ansorg, K.-D. Müller, G. Von Recklinghausen, H.P. Nalik. Int. J. Med. Microbiol. 276 (1992) 323-329. 
95. C. Wunder, Y. Churin, F. Winau, D. Warnecke, M. Vieth, B. Lindner, U. Zahringer, H.J. Mollenkopf, E. Heinz, T.F. Meyer. Nat. Med. 12 (2006) 1030-1038.

96. C.-H. Lai, Y.-M. Hsu, H.-J. Wang, W.-C. Wang. BioMedicine 3 (2013) 27-33.

97. K. Hosoda, H. Shimomura, S. Hayashi, K. Yokota, Y. Hirai. FEMS Microbiol. Lett. 318 (2011) 68-75.

98. R.D. Leunk, P.T. Johnson, B.C. David, W.G. Kraft, D.R. Morgan. J. Med. Microbiol. 26 (1988) 93-99.

99. T.L. Cover, M.J. Blaser. J. Biol. Chem. 267 (1992) 10570-10575.

100. E. Papini, M. Zoratti, T.L. Cover. Toxicon 39 (2001) 1757-1767.

101. J. Rassow, M. Meinecke. Microbes Infect. 14 (2012) 1026-1033.

102. G. Moll, E. Papini, R. Colonna, D. Burroni, J. Telford, R. Rappuoli, C. Montecucco. Eur. J. Biochem. 234 (1995) 947-952.

103. C. Pagliaccia, X.-M. Wang, F. Tardy, J.L. Telford, J.-M. Ruysschaert, V. Cabiaux. Eur. J. Biochem. 267 (2000) 104-109.

104. P. Boquet, V. Ricci. Trends Microbiol. 20 (2012) 165-174.

105. H. Iwamoto, D.M. Czajkowsky, T.L. Cover, G. Szabo, Z. Shao. FEBS Lett. 450 (1999) 101-104.

106. P. Lusini, N. Figura, M. Valassina, F. Roviello, C. Vindigni, L. Trabalzini, R. Nuti, C. Lenzi, C. Gonnelli, M. Nardi, P. Martelli, A. Santucci. Dig Liver Dis. 37 (2005) 232-239.

107. T. Tannaes, I.K. Bukholm, G. Bukholm. FEMS Immunol. Med. Microbiol. 44 (2005) 17-23.

108. Y.-L. Lin, J.-S. Liu, K.-T. Chen, C.-T. Chen, E.-C. Chan. FEBS Lett. 423 (1998) 249-253.

109. N. Dorrell, M.C. Martino, R.A. Stabler, S.J. Ward, Z.W. Zhang, A.A. McColm, M.J.G. Farthing, B.W. Wren. Gastroenterology 117 (1999) 1098-1104.

110. D.T. Smoot. Gastroenterology 113 (1997) S31-S34.

111. J.I. Smith, B. Drumm, A.W. Newmann, Z. Policova, P.M. Sherman. Infect. Immun. 58 (1990) 3056-3060.

112. H. Pruul, C.S. Goodwin, P.J. McDonald, G. Lewis, D. Pankhurst. J. Med. Microbiol. 32 (1990) 93-100.

113. J.S. Gunn, K.B. Lim, J. Krueger, K. Kim, L. Guo, M. Hackett, S.I. Miller. Mol. Microbiol. 27 (1998) 1171-1182.

114. T.W. Cullen, D.K. Giles, L.N. Wolf, C. Ecobichon, I.G. Boneca, M.S. Trent. PLoS Pathog. 7 (2011) 1-18.

115. A.X. Tran, J.D. Whittimore, P.B. Wyrick, S.C. McGrath, R.J. Cotter, M.S. Trent. J. Bacteriol. 188 (2006) 4531-4541.

116. D. Ilver, A. Arnqvist, J. Ogren, I.-M. Frick, D. Kersulyte, E.T. Incecik, D.E. Berg, A. Covacci, L. Engstrand, T. Bore, Science, 279 (1998) 373-377.

117. J. Mahdavi, B. Sonden, M. Hurtig, F.O. Olfat, L. Forsberg, N. Roche, J. Angstrom, T. Larsson, S. Teneberg, K.A. Karlsson, S. Altraja, T. Wadstrom, D. Kersulyte, D.E. Berg, A. Dubois, C. Petersson, K.E. Magnusson, T. Norberg, F. Lindh, B.B. Lundskog, A. Arnqvist, L. Hammarstrom, T. Boren. Science 297 (2002) 573-578.

118. M. Aspholm, A. Kalia, S. Ruhl, S. Schedin, A. Arnqvist, S. Lindén, R. Sjöström, M. Gerhard, C. Semino-Mora, A. Dubois, M. Unemo, D. Danielsson, S. Teneberg, W.K. Lee, D.E. Berg, T. Borén. Methods. Enzymol. 417 (2006) 293-339.

119. A. Magalhães, C.A. Reis. Braz. J. Med. Biol. Res. 43 (2010) 611-618.

120. A.O. Elzoghby, W.M. Samy, N.A. Elgindy. J. Control. Release 161 (2012) 38-49. 
121. S.K. Jain, M.S. Jangdey. Mol. Pharm. 6 (2008) 295-304.

122. S.K. Jain, M. Gupta, A.K. Sahoo, A.N. Pandey, A.K. Jain. Curr. Sci. 106 (2014) 267-276.

123. P.L. Bardonnet, V. Faivre, F. Pirot, P. Boullanger, F. Falson. Biochem. Biophys. Res. Commun. 329 (2005) 1186-1192.

124. Y.H. Lin, S.C. Tsai, C.H. Lai, C.H. Lee, Z.S. He, G.C. Tseng. Biomaterials 34 (2013) 4466-4479.

125. J.A. Raval, J.K. Patel, M.M. Patel. Acta Pharm. 60 (2010) 455-465.

126. Z. Liu, W. Lu, L. Qian, X. Zhang, P. Zeng, J. Pan. J. Control. Release 102 (2005) 135-144.

127. A.O. Adebisi, B.R. Conway. Int. J. Pharm. 470 (2014) 28-40.

128. J.K. Patel, J.R. Chavda. J. Microencapsulation 26 (2009) 365-376.

129. S. Hassani, Y. Pellequer, A. Lamprecht. Pharm. Res. 26 (2009) 1149-1154.

130. S. Arora, J.M. Rajwade, K.M. Paknikar. Toxicol. Appl. Pharmacol. 258 (2012) 151-165. 